\title{
IMPLEMENTASI SISTEM KOLABORASI SEBAGAI PENDUKUNG DISTRIBUSI PRODUK PADA CITY COURIER
}

\author{
Ai Rosita ${ }^{1)}$, Supriady ${ }^{2)}$, Maniah $^{3)}$ \\ ${ }^{1)}$ Program Studi Teknik Informatika \\ Universitas Widyatama \\ Jl. Cikutra no. 204 A Bandung \\ ${ }^{2,3)}$ Jurusan Teknik Informatika \\ Politeknik Pos Indonesia \\ J1. Sariasih no.54 Bandung \\ 1)ai.rosita@widyatama.ac.id, ${ }^{2)}$ goku_sakti2005@yahoo.com
}

\begin{abstract}
Abstrak
Penyediaan sistem kolaborasi untuk mendukung kelancaran operasional bisnis merupakan kebutuhan yang esensial, terutama bagi organisasi yang tersebar pada rentang geografis yang luas dan melibatkan banyak orang dalam aktivitas bisnisnya. Sebuah sistem kolaborasi berperan memfasilitasi terjadinya workflow proses bisnis yang sudah disusun dengan cara menyediakan sarana berbagi informasi dan komunikasi di semua partisipan proses.
\end{abstract}

Penelitian ini akan membahas tahapan implementasi rancangan sistem kolaborasi untuk mendukung distribusi barang pada perusahaan City Courier, yaitu sebuah perusahaan jasa pengiriman barang dengan agen dan lokasi yang tersebar di beberapa kota. Pendekatan yang digunakan pada perancangan ini adalah pendekatan berorientasi obyek, dan hasil rancangan diharapkan dapat dijadikan pedoman dalam implementasi sistem berupa pengembangan software sesuai dengan konsep rancangan yang sudah disusun.

Kata kunci :

Workflow, kolaborasi, rancangan, obyek.

\section{Abstract}

Providing collaboration system to support the smooth operation of the business is an essential requirement, especially for organizations that operates over wide geographical range and involves many people in their business activities. Collaboration system can be an enabler that facilitate organization in implementing of business process workflow that has been defined, by providing information sharing and communication across all process participants.

This paper will discuss the design phase of collaboration system to support the distribution process on City Courier, a freight company that has agents and locations in several cities. The approach used in this design is the object-oriented approach, and the results of the draft is expected to be used as guidelines in the software development in accordance with the design concept that has been defined.

Keywords :

Workflow, collaboration, design, object

\section{Pendahuluan}

Perancangan sistem merupakan salah satu tahapan penting dalam pengembangan sistem informasi. Proses perancangan sistem yang baik akan menjamin tercapainya tujuan pengembangan sistem. Hasil perancangan sistem merupakan pedoman utama dalam proses implementasi rancangan menjadi software yang siap pakai.

Perancangan sistem perlu mengacu pada analisis kebutuhan sistem itu sendiri karena hasil rancangan seharusnya dapat ditelusuri kembali berdasarkan statemen kebutuhan. Agar efektif, perancangan sistem sebaiknya mengacu pada pendekatan tertentu yang nantinya akan konsisten dengan implementasi rancangan.

Pada penelitian ini akan dibuat satu rancangan sistem yang mengacu pada identifikasi kebutuhan sistem yang sudah ditetapkan sebelumnya. Rancangan ini dibuat dengan pendekatan berorientasi obyek, dikarenakan pada tahapan implementasi, rancangan 
ini akan diwujudkan melalui paradigma pemrograman berorientasi obyek.

Perancangan sistem yang akan dibuat yaitu berdasarkan identifikasi kebutuhan pengembangan sistem kolaborasi untuk mendukung transformasi multi produk pada perusahaan City Courier. Perusahaan City Courier adalah perusahan jasa layanan pengiriman barang yang mendistribusikan barang titipan dari pengirim ke penerima (point to point). Sistem kolaborasi dibangun sebagai reaksi terhadap permasalahan yang dihadapi oleh City Courier akibat perkembangan kompleksitas kondisi transportasi saat ini. Beberapa masalah yang dihadapi antara lain: pemborosan penggunaan bahan bakar minyak, dan kurang efektifnya waktu tempuh sehingga berakibat pada keterlambatan pendistribusian komoditas.

Untuk mengatasi hal tersebut, diperlukan fasilitas informasi dan basis data lengkap terkait operator kurir yang ada untuk kemudian dilakukan pendataan dan rekapitulasi nama perusahaan, jumlah armada, kapasitas angkut yang tersedia, serta jalur yang digunakan.

\section{LANDASAN TEORI}

\section{II.1 Supply Chain Management}

Supply chain dan supply chain management (SCM) merupakan dua istilah yang seringkali salah dipersepsikan di berbagai artikel. Cooper (1997) menyebutkan istilah SCM baru muncul sekitar tahun 90 an dan diperkenalkan oleh konsultan manajemen. Saat ini bidang SCM merupakan bidang kajian menarik dan banyak didiskusikan oleh berbagai pihak baik industri maupun akademisi.

Supply chain didefinisikan sebagai aktivitas yang meilibatkan banyak pihak dalam mentransformasi dan distribusi barang mulai dari bahan baku hingga menjadi produk yang diterima oleh konsumen akhir. Sebuah supply chain terdiri atas perusahaan yang menyediakan dan mengangkut bahan baku dari alam, mentransformasi bahan baku menjadi bahan setengah jadi dan perusahaan perakitan, distributor dan retailer yang menjual produk ke konsumen akhir (Anwar, 2011).

Beberapa pihak yang terlibat pada supply chain antara lain adalah (Anwar, 2011):

1. Supplier

2. Manufacturer
3. Distributor

4. Retail outlet

5. Customer

Secara umum supply chain terdiri atas beberapa chain yang terus berkembang sebagai berikut:

1. Chain 1: supplier, yang merupakan awal jaringan tempat bahan baku diproduksi.

2. Chain 1-2-3: supplier-manufacturersdistribution, yang merupakan alur perjalanan barang dari bahan baku hingga ke perusahaan yang menyebarkan barang kepada pelanggan

3. Chain 1-2-3-4: supplier-manufacturersdistribution-retail outlet, merupakan alur perjalanan barang hingga ke toko tempat konsumen memperoleh barang.

4. Chain 1-2-3-4-5: supplier-manufacturersdistribution-retail, outlet-customer, merupakan mata rantai perjalanan barang hingga sampai ke tangan konsumen.

Penerapan SCM di suatu industri/bisnis dapat mendatangkan berbagai keuntungan, hal ini karena sistem SCM memiliki beberapa fungsional penting sebagai berikut (Watanabe, 2001):

1. Demand management/forecasting, karena sistem SCM biasanya dilengkapi dengan alat bantu berupa teknik peramalan secara statistik untuk kepentingan prediksi pengadaan barang

2. Advanced planning and scheduling, merupakan alat bantu dalam membuat perencanaan jangka menengah dan panjang sebagai pertimbangan dalam pengambilan keputusan strategis.

3. Transportation management, merupakan fungsi yang terkait dengan proses pendistribusian produk dalam SCM

4. Distribution and deployment, merupakan alat bantu perencanaan yang dapat menyeimbangkan dan mengoptimalkan jaringan distribusi.

5. Production planning, merupakan perencanaan produksi supaya mencapai hasil yang optimal

6. Available to promise, sistem cepat tanggap yang mempertimbangkan alokasi, sumberdaya, kapasitas produksi dan kapasitas transportasi serta biaya keseluruhan dalam rantai pasok.

7. Supply chain modeler, merupakan alat bantu simulasi untuk mengujicoba model prediksi dan estimasi atas rencana yang akan dibuat

8. Optimizer, merupakan pusat pemodelan pada sistem SCM yang memuat berbagai algoritma komputasi seperti linier programming, non linier 
programming, genetic algorithm dan lain-lain yang digunakan untuk melakukan optimasi atas proses perencanaan.

\section{II.2 Sistem Kolaborasi}

Sistem kolaborasi adalah seperangkat alat bantu berbasis teknologi informasi yang membantu menyediakan alur kerja (workflow) informasi untuk setiap anggota tim tertentu (Bafousou, 2003). Sistem ini memfasilitasi agar setiap anggota tim dapat berbagi ide dan informasi sehingga tugas kelompok dapat dikerjakan lebih cepat dan efisien. Secara umum terdapat dua jenis system koloborasi yaitu (www.computerbusinessresearch.com):

1. Kolaborasi tidak terstruktur: setiap anggota memberikan jawaban atas satu pertanyaan yang diberikan secara acak, dan system memfasilitasi diskusi bebas

2. Kolaborasi terstruktur: system memberikan batasan dan memfasilitasi proses pembagian informasi, pengetahuan umum, dan aturan tertulis, struktur dan aturan workflow tidak berubah.

Penerapan sistem kolaborasi harus memperhatikan kultur organisasi. Kolaborasi terstruktur tidak cocok di organisasi yang relative dinamis dan tidak memiliki budaya hirarki seperti google, sistem ini lebih cocok di organisasi dengan industro yang sudah stabil seperti manufaktur.

Untuk melakukan kolaborasi antara pengguna di dalam satu unit organisasi, dibutuhkan suatu media interaksi yang menjembatani pengguna berkolaborasi. Teknologi informasi telah memberikan solusi media interaksi dalam melakukan kolaborasi untuk bertukar dan berbagi informasi secara cepat dan mudah

Kehadiran teknologi web sangat mendukung terjadinya kolaborasi. Kolaborasi berbasis web dapat memfasilitasi organisasi untuk berkolaborasi dengan konsumen maupun internal melalui internet secara real-time. Aplikasi kolaborasi berbasis web biasanya berupa software back-end atau service yang dapat digunakan sebagai fasilitas berinteraksi dengan konsumen (Bafousou, 2003)

Selain koloborasi berbasis web, masih banyak alternatif alat bantu kolaborasi lain seperti (collaboration-software.financesonline.com):
1. Komunikasi, yang meliputi: konferensi sinkron maupun ansinkron, email, voice mail, wikis, web publishing.

2. Konferensi: yang meliputi internet forum, online chat, instant messaging, video conference, data conference, dan application sharing.

3. Kordinasi: mengacu pada alat bantu yang lebih kompleks seperti kalender elektronik, online proofing, project management system, workflow system, Knowledge management system, market prediction, social software system, dan banyak lagi.

\section{II.3 Tahapan Perancangan Berorientasi Obyek}

Analisis dan perancangan berorientasi obyek atau object oriented analysis and design (OOAD) merupakan salah satu pendekatan pemodelan proses dan perancangan sistem berbasis responsibility atau responsibility driven design (RDD)(Din dan Idris, 2009). RDD membagi desain OO menjadi 2 fase yaitu exploratory phase dan analysis phase. Sedangkan tahapan perancangan berorientasi obyek menurut Booch terdiri atas 4 fase utama yaitu (Din dan Idris, 2009):

1. Identifikasi kelas

2. Identifikasi semantik kelas

3. Identifikasi relasi antar kelas

4. Menentukan interface dan implementasi kelas.

Gambar 1 menampilkan keterkaitan antar setiap tahapan.

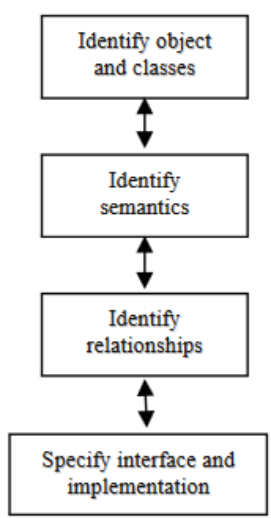

Gambar 1. Tahapan Perancangan Berorientasi Obyek (Din dan Idris, 2009) 


\section{Perancangan Sistem}

\section{III.1 Identifikasi Kebutuhan}

Berdasarkan hasil analisis terhadap kondisi proses bisnis di City Courier, didapat gambaran aliran data dan informasi sebagai pedoman dalam menyusun identifikasi kebutuhan. Pengguna yang terlibat dalam kolaborasi ini adalah seluruh user yang telah terdaftar sebelumnya. Proses peengajuan layanan bisa dilakukan melalui SMS atau aplikasi web site. Ketika sebuah permintaan layanan di submit sistem akan merespon dengan melakukan transmisi order ke kantor pos terdekat dimana lokasi pelanggan berada. Setiap jasa layanan akan ditagihkan melalui billing bulanan yang akan disampaikan kepada pelanggan. Proses bisnis ini dapat dilihat pada gambar 2.

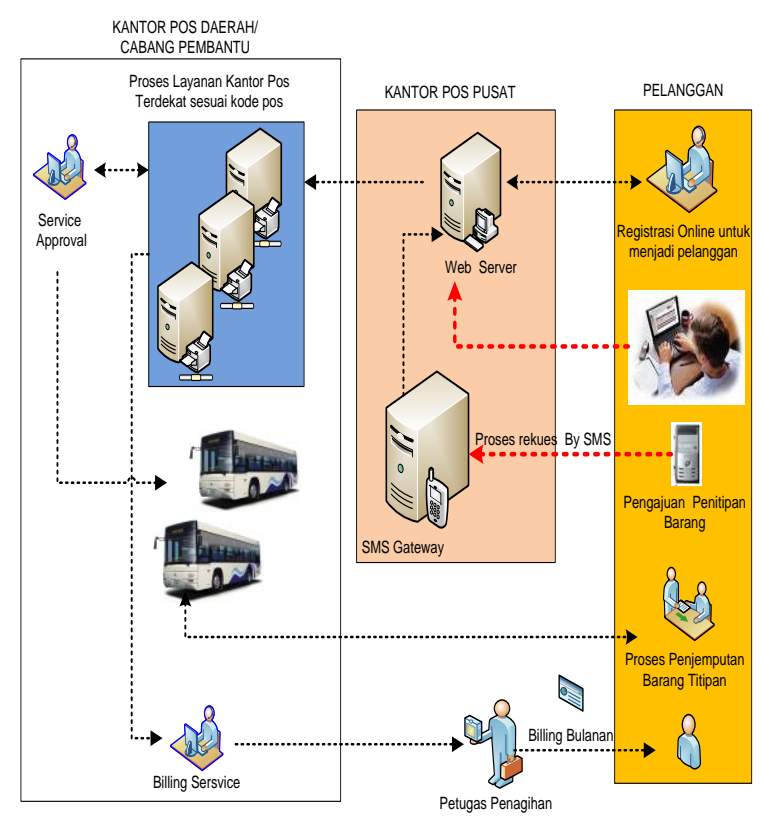

\section{Gambar 2. Proses Bisnis Distribusi Produk di City Courier}

Sebagai landasan identifikasi kebutuhan, digunakan 7 atribut kriteria kualitas informasi yaitu relevance, capacity, timeliness, accessability, flexibility, accuracy dan security. Untuk masingmasing atribut diidentifikasi kebutuhan yang sesuai dengan kondisi di City Courier. Tabel 1 menampilkan hasil analisis kebutuhan berdasarkan 7 atribut kualitas informasi.
Berdasarkan hasil analisis kebutuhan, kemudian didefnisikan fitur-fitur utama sistem sebagai berikut:

1. Akses melalui userid dan password

2. Registrasi online

3. Approve pendaftar

4. Pesan jasa pengiriman via web

5. Pesan jasa pengiriman via sms

6. Melihat billing pembayaran via web

7. Melihat billing pembayaran via sms

8. Melihat status transaksi pengiriman

9. Cek rekening pembayaran pelanggan

Tabel 1. Identifkasi Kebutuhan Sistem

$\begin{array}{ll}\text { Kebutuhan } & \text { Atribut } \\ & \text { Kualitas } \\ \text { Informasi }\end{array}$

Dibutuhkan sistem yang relevan dengan kebutuhan PT. POS Indonesia sebagai perusahaan yang bergerak di bidang jasa pengiriman barang diamana keutuhan yang semakin hari diperkirakan akan semakin banyak.

Dibutuhkan kapasitas penyimpnan data yang sangat besar untuk menampung kebutuhan penyimpanan data user yang semakin meningkat.

Dibutuhkan Waktu pemprosesan yang sangat singkat untuk menangani user yang banyak.

Dibutuhkan kecepatan akses data yang memadai pula serta tampilan yang user friendly.

Dibutuhkan Template yang responsive untuk kebutuhan sistem di era mobile sekarang, dimana aplikasi dapat diakses melalui berbagai platform.

Relevance

Capacity

Dibutuhkan kecepatan dan keakuratan Accuracy pemprosesan data.

Dibutuhkan Enkripsi data seperti https. Security 


\section{III.2 Model Interaksi Sistem}

Agar fitur di atas dapat direalisasikan dalam bentuk class, maka perlu didefinisikan diagram interaksi untuk masing-masing fitur. Melalui diagram interaksi, dapat didefinisikan obyek-obyek yang terlibat serta peranan masing-masing obyek. Diagram interaksi disajikan dalam bentuk sequence diagram.

\section{III.2.1 Sequence Diagram Registrasi Online}

Pada proses Registrasi Online, aksi sistem yang pertama dilakukan adalah memunculkan obyek form aplikasi Registrasi. Ketika calon pelanggan melakukan aksi submit form, obyek tersebut melakukan hyperlink ke RegisterController. Selanjutnya Register Controller memanggil method ValidateData() untuk mengecek apakah data tersebut valid atau belum, kalau sudah controller mernanggil method CreateKdPelanggan() untuk memasukan data dengan bantuan database services yang memiliki method InsertDataPelanggan(). Sequence diagram registrasi online dapat dilihat pada gambar 3.

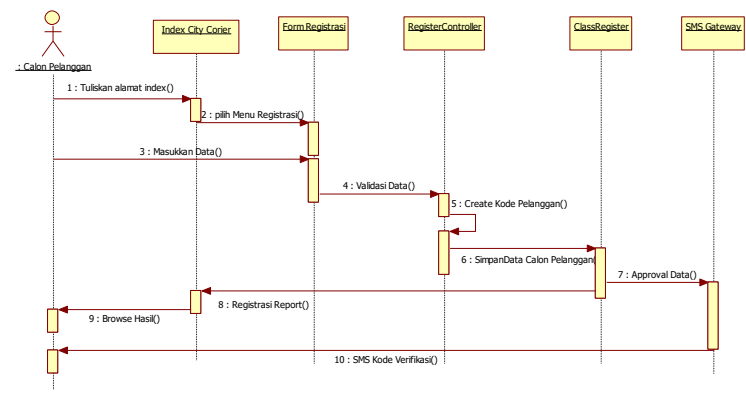

Gambar 3 Sequence Diagram Registrasi Online

\section{III.2.2 Sequence Diagram login}

Pada proses login, aksi sistem yang pertama dilakukan adalah memunculkan obyek form login. Kemudian pengguna melakukan submit password yang diterirna LoginController. LoginController selanjutnya menggunakan method getPassword (UserlD,Password). Jika password diterima, maka menu index dibuka disertai dengan aktifnya LoginDelayTimer(). Gambar 4 menampilkan sequence diagram untuk proses login.

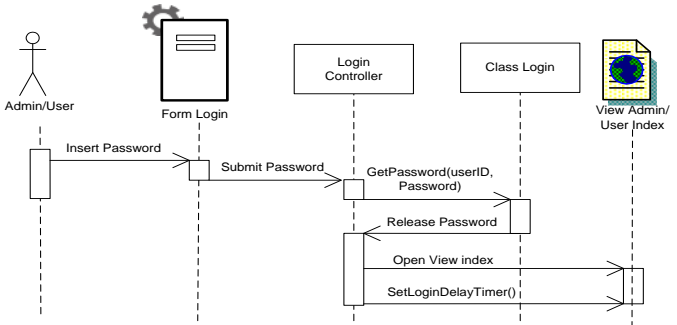

Gambar 4. Sequence Diagram login

\section{III.2.3 Sequence Diagram Approve Calon Pelanggan}

Pada proses Approve Calon Pelanggan, aksi sistem yang pertama dilakukan adalah memunculkan obyek form aplikasi Registrasi. Ketika calon pelanggan melakukan aksi submit form, obyek tersebut melakukan hyperlink ke RegisterController. Selanjutnya Register Controller memanggil method ValidateData0untuk mengecek apakah data tersebut valid atau belum, kalau sudah controller memanggil method CreateKdPelanggan() untuk memasukan data dengan bantuan database services yang memiliki method InsertDataPelanggan(). Gambar 5 menampilkan sequence diagram untuk proses approve registrasi calon pelanggan

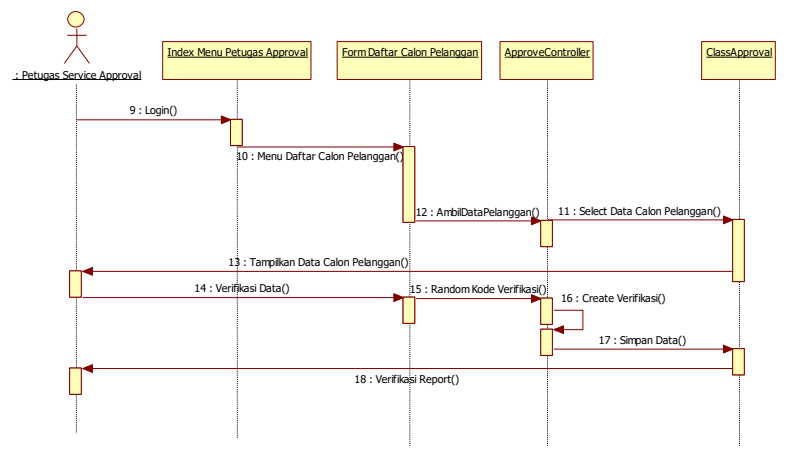

Gambar 5. Sequence Diagram Approve Calon Pelanggan

\section{III.2.4 Sequence Diagram Pemesanan Jasa via Web}

Pada proses pemesanan jasa via web, setelah melakukan login, pelanggan dapat memilih menu pemesanan, mengisi form pemesanan dan pada controller pemesanan, data tersebut akan diproses untuk diteruskan ke class pemesanan. Data yang

Ai Rosita, Supriady, Maniah 
sudah di-approve akan diteruskan ke obyek SMSGateway yang kemudian akan mengirimkan pesan kepada pelanggan. Gambar 6 menampilkan sequence diagram untuk proses pemesanan melalui web.

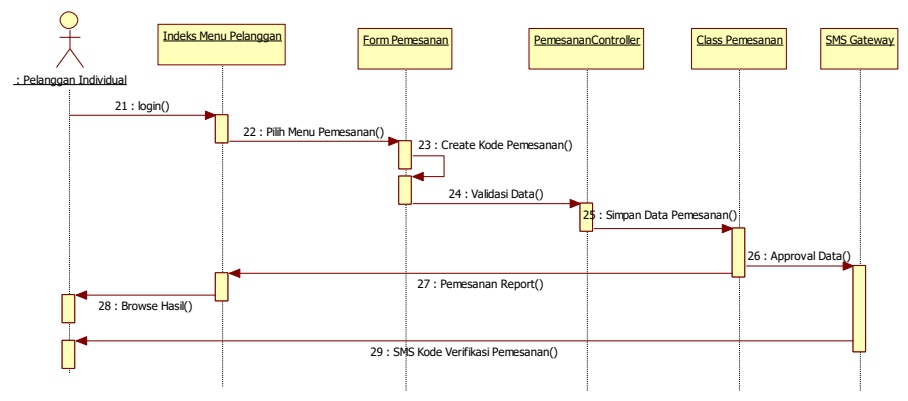

Gambar 6 Sequence Diagram Pemesanan Jasa via Web

Sedangkan untuk pemesanan via sms melalui proses interaksi yang hampir serupa sehingga tidak digambarkan.

\section{III.2.5 Sequence Diagram Cetak Billing Pembayaran pelanggan}

Pada proses cetak billing pembayaran, petugas billing service dapat mengaksesnya melalui form billing dengan memasukkan data pemesanan berdasarkan identitas pelanggan. Selanjutnya data akan diambil dari class billing dan dikembalkan ke petugas berupa dokumen pembayaran billing. Gambar 7 menampilkan sequence diagram untuk proses pencetakan billing pembayaran.

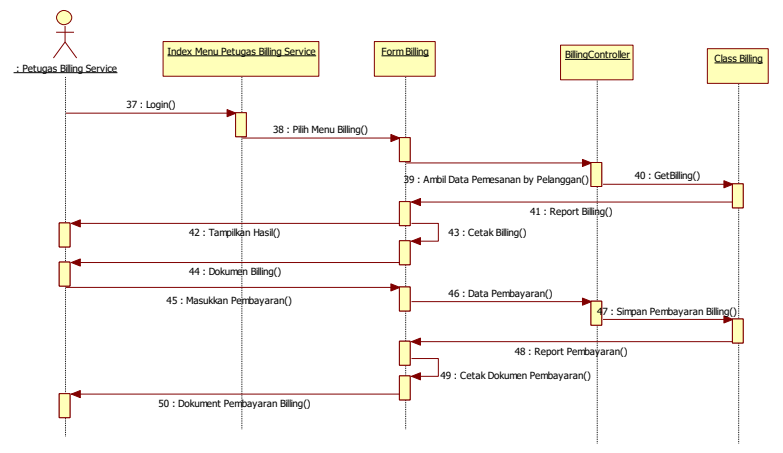

Gambar 7 Sequence Diagram Cetak Billing Pembayaran pelanggan

\section{III.3 Perancangan Diagram Kelas}

Tahapan selanjutnya adalah perancangan class yang merupakan representasi object yang terlibat dalam sistem. Berdasarkan identifkasi data dan obyek yang diperlukan, hasil dari tahap analisis, dapat diidentifikasi kelas-kelas yang diperlukan. Struktur kelas-kelas ini disusun sedemikian rupa agar dapat diimplementasikan menggunakan framework Zend, yang menerapkan konsep MVC (Model-ViewController) (Zend Framework, 2008), sehingga interaksi antara class tampilan (GUI, Graphical User Interface) dengan class yang berhubungan dengan data, tidak dapat dilakukan secara langsung, karena dilakukan melalui class controller. Gambar 10 menampilkan hasil perancangan class pada sistem kolaborasi yang akan dikembangkan.

\section{III.4 Perancangan Metoda Interaksi}

Setelah melakukan perancangan interaksi antar kelas dan sequence diagram untuk masing-masing proses yang terdapat di dalam City Courier, tahap selanjutnya adalah merancang metoda interaksi untuk masing-masing proses. Pada tahap ini diharapkan dapat merepresentasikan algoritma setiap proses melalui visualisasi state diagram. Berikut beberapa rancangan state diagram

\section{III.4.1 State Diagram Calon Pelanggan menjadi Pelanggan}

State diagram ini menggambarkan proses perubahan status dari calon pelanggan menjadi pelanggan. Gambar 8 menampilkan state diagram calon pelanggan menjadi pelanggan.

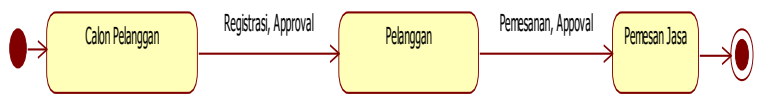

\section{Gambar 8 State Diagram Calon Pelanggan menjadi Pelanggan}

Proses pada State Diagram diatas dapat dijelaskan sebagai berikut:

a. Calon Pelanggan akan berubah status menjadi Pelanggan setelah melakukan registrasi dan mendapatkan approval dari petugas Approval City Courier.

b. Pelanggan akan berubah status menjadi Pemesan Jasa setelah melakukkan pemesanan terhadap jasa City Courier. 


\section{III.4.2 State Diagram Pemesanan Jasa}

Proses pemesanan jasa pengiriman barang dapat digambarkan melalui state diagram pemesanan jasa seperti yang terlihat pada gambar 9 .

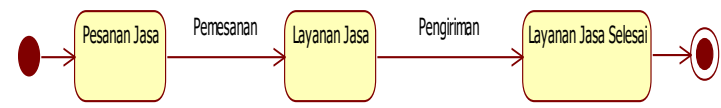

Gambar 9 State Diagram Pemesanan Jasa
Proses pada State Diagram gambar 9 dapat dijelaskan sebagai berikut:

a. Pesanan Jasa Pengiriman akan berubah status menjadi Layanan Jasa setelah adanya pemesanan dari pelanggan.

b. Layanan Jasa akan selesai setelah terjadi pengiriman terhadap pemesanan jasa dimaksud.

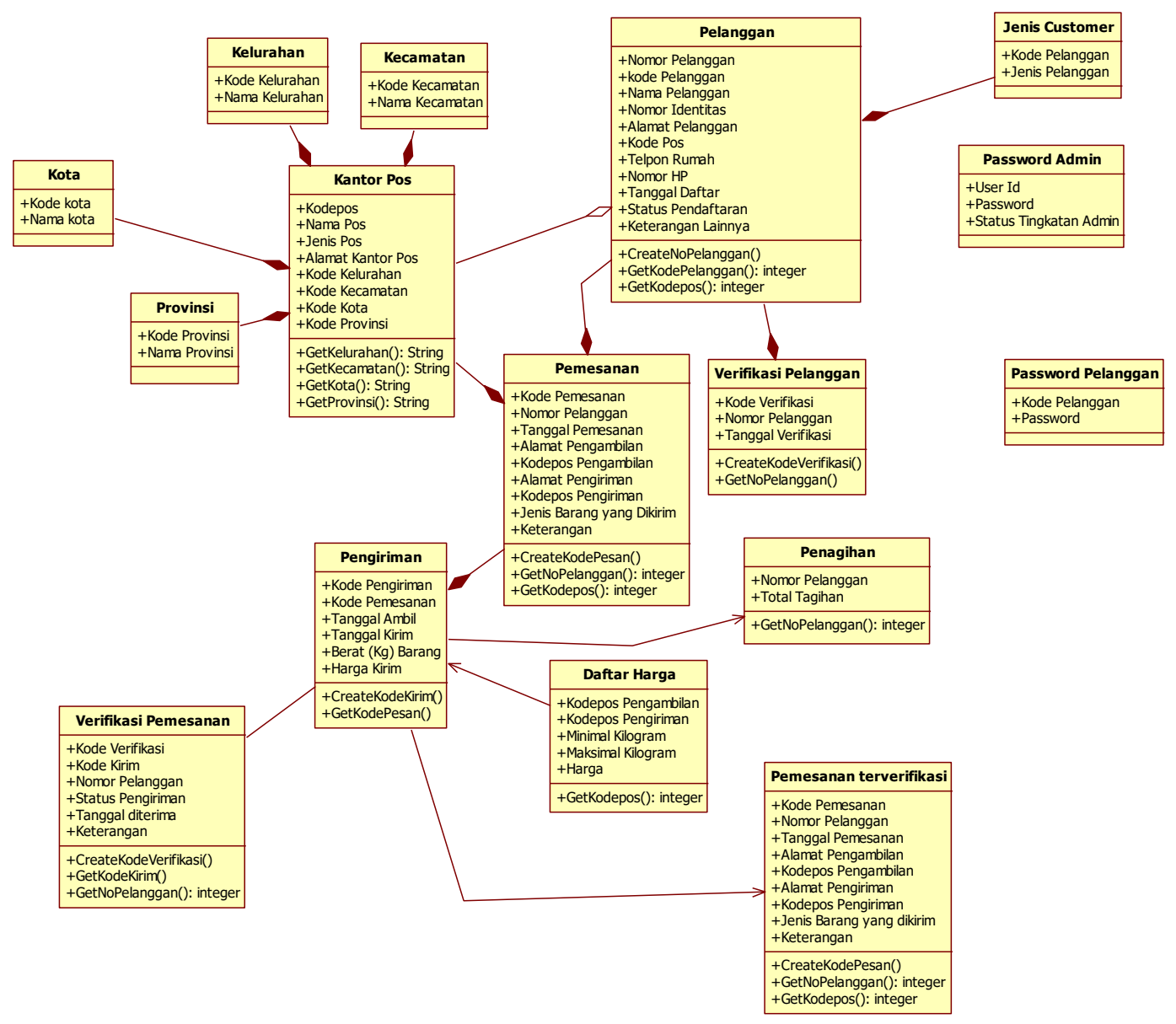

Gambar 10. Class Diagram Sistem Kolaborasi

\section{III.4.3 State Diagram Billing Pelanggan}

State diagram yang cukup penting lainnya adalah yang menggambarkan perubahan kondisi status pemesanan pelanggan, dari keadaan belum dibayar hingga konfirmasi sudah dibayar. Gambar 10 menampilkan state diagram perubahan status ini.

Ai Rosita, Supriady, Maniah 


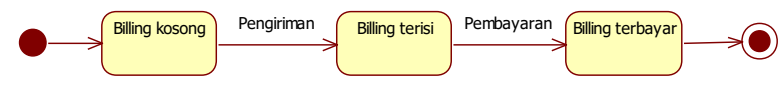

Gambar 11. State Diagram Billing Pelanggan

Proses pada State Diagram diatas dapat dijelaskan sebagai berikut:

a. Pelanggan akan memiliki billing awal kosong dan kemudian akan terisi jika jasa pengiriman telah selesai dilakukan.

b. Status billing terbayar akan muncul setelah terjadi transaksi pembayaran billing pemesanan Jasa

\section{Perancangan Antar Muka}

Setelah melakukan perancangan metode interaksi antara aktor dengan sistem City Corier, tahap berikutnya adalah merancang antarmuka pengguna, yaitu membuat interface sebagai alat komnunikasi aktor dengan sistem.

\section{IV.1.1 Registrasi Online}

Tampilan ini merupakan tampilan form registrasi untuk Customer agar mendapatkan akses untuk melakukan booking pengiriman. Gambar 12 menampilkan form registrasi untuk calon customer.

\begin{tabular}{|c|c|}
\hline REGISTRASI & \begin{tabular}{|l|} 
Batal \\
\end{tabular} \\
\hline LOGO & Header Form Registrasi \\
\hline FORM REGISTRASI & 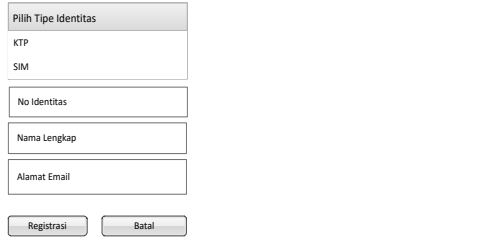 \\
\hline
\end{tabular}

Gambar 12 Tampilan Registrasi Online

\section{IV.1.2 Billing Customer}

Tampilan ini digunakan untuk menayangkan Billing Customer. Tampilan ini berisi menu - menu yang dibutuhkan oleh Customer seperti : Booking, Data Pengiriman dan data akun. Gambar 13 menampilkan rancangan panel Billing Customer.

\section{IV.1.3 Billing Operator}

Tampilan ini akan digunakan digunakan operator di setiap kantor cabang untuk melihat status pengiriman dan pembayaran, dengan data yang disajikan secara realtime. Gambar 14 menampikan rancangan panel Billing untuk operator/petugas

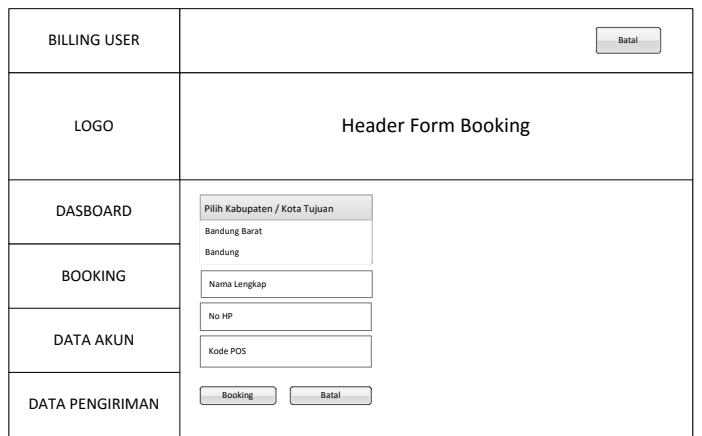

Gambar 13 Tampilan Billing Custom

\begin{tabular}{|c|c|}
\hline BILLING OPERATOR & Header Dashboard \\
\hline LOGO & \\
\hline DASBOARD & \\
\hline BOOKING & \\
\hline DATA AKUN & \\
\hline DATA PENGIRIMAN & \\
\hline
\end{tabular}

Gambar 14 Tampilan Billing Operator

\section{RANCANGAN JARINGAN UNTUK 3 KOTA (BANDUNG, TASIK DAN GARUT)}

Sistem kolaborasi ini akan diimplementasi di tiga kota yaitu Bandung,Tasikmalaya dan Garut. Oleh karena itu, selain perancangan sistem dan antarmuka, perlu juga disiapkan rancangan jaringan komputer sebagai infrastruktur pendukung.

Jenis Jaringan yang dirancang adalah Jaringan terpusat (Centralized), artinya semua data baik milik pelanggan atau perusahaan terpusat pada satu server. Jenis ini memudahkan petugas baik di Kantor Pusat ataupun Cabang dalam transaksi data, sehingga tak perlu repot menyimpan data di tiap cabang. Selain itu, server yang dirancang ada dua jenis, yaitu cloud dan fisik. Hal ini dilakukan agar tidak terjadinya hilang data. Cloud server digunakan untuk keperluan transaksi data yang bersifat jangka panjang. Sedangkan Server fisik digunakan untuk jangka panjang, namun bersifat temporary. Karena server fisik memiliki kapasitas penyimpanan yang terbatas, 
maka untuk menghemat biaya cloud server digunakan.

Jaringan yang bersifat Centralized ini tidak hanya bisa digunakan pada sistem $3 \mathrm{kota} / \mathrm{cabang}$, namun bisa digunakan untuk lebih dari 3 kota/cabang. Hal ini didukung dengan rancangan jaringan yang memakai dua jenis server. Konfigurasi jaringan yang akan digunakan sebagai platform berjalannya sistem ini dapat dilihat pada gambar 15 .

Kekurangan dari sistem centralized ini adalah jika data di server hilang, maka transaksi data tidak akan berjalan. Selain itu, jika keamanan server tidak dioptimalkan, maka data rentan dimanipulasi oleh pihak yang tidak bertanggung jawab.

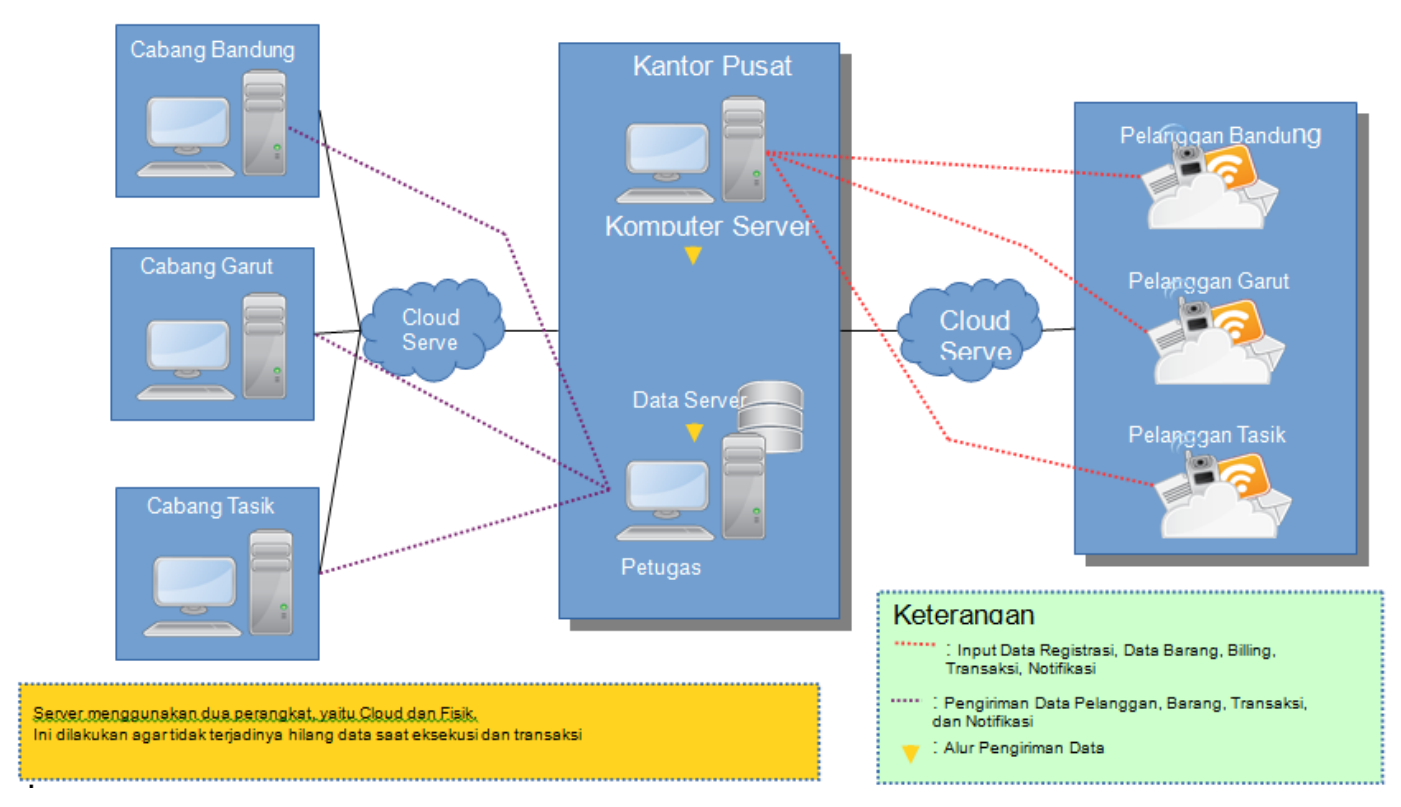

Gambar 15. Rancangan Jaringan Infrastruktrur Sistem Kolaborasi untuk 3 Kota

Dukungan cloud server untuk Sistem Centralized ini mempengaruhi keamanan data dan transaksi. Perusahaan harus bekerjasama dengan ISP yang memiliki Cloud server dengan kualitas keamanan yang baik serta kapasitas penyimpanan yang besar. Perusahaan Kurir bisa saja membuat cloud server sendiri, namun itu tidak akan efektif dan malah akan membuat pembengkakan biaya yang lebih besar.

Berdasarkan pertimbangan di atas, perlu didefinsikan juga spesifikasi server yang dianggap cukup memadai untuk mendukung sistem kolaborasi ini. Tabel 2 menampilkan rekomendasi spesifikasi server untuk pendukung sistem kolaborasi yang dapat melayani 3 kota, sedangkan spesifkasi server untuk kantor pusat ditampilkan pada tabel 3.
Tabel 2. Spesifikasi Server Pendukung Sistem Kolaborasi untuk Melayani 3 Kota.

\begin{tabular}{|c|c|c|c|}
\hline No & Nama & Qty & Deskripsi \\
\hline 1 & $\begin{array}{l}\text { Server } \\
\text { Processor }\end{array}$ & 1 & $\begin{array}{lr}\text { intel E3-1220V2 } \\
(3.10 \mathrm{Ghz}, & \text { C8Mb, } \\
\text { LGA1155) } & \\
\text { Processor } & \text { LGA } \\
1155 & \end{array}$ \\
\hline 2 & $\begin{array}{l}\text { Server } \\
\text { Motherboard }\end{array}$ & 1 & $\begin{array}{l}\text { intel S1200BTSR } \\
\text { intel Socket } 1155\end{array}$ \\
\hline 3 & $\begin{array}{l}\text { Server } \\
\text { Memory }\end{array}$ & 2 & $\begin{array}{l}\text { V-GEN 4Gb PC } \\
12800 / 1600 \text { ECC } \\
\text { Memory }\end{array}$ \\
\hline 4 & $\begin{array}{l}\text { Server } \\
\text { Harddisk }\end{array}$ & 1 & \begin{tabular}{lll}
\multicolumn{2}{l}{ Seagate } & \\
Constellation & ES \\
SATA III 1 & TB \\
$7200 \quad$ RPM & for \\
server & &
\end{tabular} \\
\hline 5 & $\begin{array}{l}\text { Server } \\
\text { Casing }\end{array}$ & 1 & $\begin{array}{l}\text { ENLIGHT EN- } \\
5801 \text { 600W Casing }\end{array}$ \\
\hline
\end{tabular}

Ai Rosita, Supriady, Maniah 
Tabel 3. Spesifikasi Server untuk Kantor Pusat

\begin{tabular}{|c|c|c|c|}
\hline No & Sparet Part & & Deskripsi \\
\hline 1 & $\begin{array}{l}\text { Server } \\
\text { Processor }\end{array}$ & 1 & $\begin{array}{lr}\text { intel } & \text { E5-2609v2 } \\
(2.40 \mathrm{ghz}, & \text { C10MB, 6.40 } \\
\text { GT/s, r } & \text { LGA2011) } \\
\text { Processor LGA 2011 }\end{array}$ \\
\hline 2 & $\begin{array}{l}\text { Server } \\
\text { Motherboard }\end{array}$ & 1 & $\begin{array}{l}\text { intel DBS2600CP2 Intel } \\
\text { Socket } 2011 \\
\text { A-Data }\end{array}$ \\
\hline 3 & $\begin{array}{l}\text { Server } \\
\text { Memory }\end{array}$ & 2 & $\begin{array}{l}\text { AD3R1600W4G11- } \\
\text { BMIE 4GB PC } 12800 \\
\text { ECC REG Memory }\end{array}$ \\
\hline 4 & $\begin{array}{l}\text { Server } \\
\text { Harddisk } \\
\text { Untuk kantor } \\
\text { Wilayah }\end{array}$ & 5 & $\begin{array}{l}\text { Seagate Constellation ES } \\
\text { SATA III } 2 \text { TB } 7200 \\
\text { RPM for server }\end{array}$ \\
\hline 5 & Server Casing & 1 & 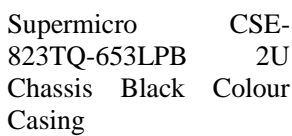 \\
\hline
\end{tabular}

\section{KESIMPULAN DAN SARAN}

Berdasarkan hasil uraian sebelumnya dapat disimpulkan hal-hal sebagai berikut:

a. Implementasi sistem seharusnya dimulai dari proses perancangan yang baik, dimana proses perancangan itu sendiri seharusnya mengacu pada hasil identifikasi kebutuhan.

b. Pada penelitian ini, sudah dibuat rancangan sistem kolaborasi yang diimplementasikan dalam bentuk pengembangan software berorientasi obyek dengan menggunakan framework Zend. Pemilihan implementasi menggunakan framework ini untuk mencegah akses langsung komponen antarmuka terhadap database dan kemudahan pemeliharaan sistem.

c. Output proses rancangan berupa diagram kelas, diagram sequence dan state-chart. Diagram-diagram di atas diperlukan untuk merealisasikan rancangan menjadi obyekobyek pada software. Rancangan juga dilengkapi dengan rancangan antarmuka dan jaringan komputer serta server yang dibutuhkan untuk implementasi sistem.

d. Kelengkapan dan kedetilan rancangan dapat memudahkan pengembang dalam merealisaskan rancangan menjadi obyek software agar sesuai dengan identifikasi kebutuhan.

\section{REFERENSI}

Anwar, SN, 2011, Manajemen Rantai Pasokan (Supply Chain Management) : Konsep dan Hakikat, Jurnal Dinamika Informatika, Vol.3 No.2.

Watanabe, R., 2001, Supply Chain Management, Konsep dan Teknologi, Majalah Usahawan No.02 Thn XXX Februari 2001.

Bafousou, Georgia, Mentzas, Gregory, 2003, A comparative Analisys of Web based Collaborative Systems, Departement of electrical and computer, National Technical University of Athens, www. Imu.iccs.ntua.gr

,Collaboration System, diakses dari http://www.computerbusinessresearch.com/Hom e/enterprise-resource-planning-andcollaborative-systems/collaboration-system

-,Classification of Collaboration Technology: Introduction for Beginners, diakses dari : https://collaboration-

software.financesonline.com/ classification-ofcollaboration-technology-introduction-forbeginners/

Din, Jamilan, and Idris, Sufian, 2009, Object-Oriented Design Process Model, International Journal of Computer Science and Network Security, Vol. 9, No. 10, October 2009.

--,(2008), Programmer's Reference Guide, Zend Framework PHP.

Ai Rosita, Supriady, Maniah 